\title{
Fuentes de información
}

\author{
Information Sources
}

Margarita Aida Cruz García ${ }^{a}$

\begin{abstract}
:
The sources of information are instruments for knowledge, access and search of information, its main objective is to search, fix and disseminate the source of information implicit in any physical support, these can be catalogued from different perspectives, however, each Author can elaborate his own classification depending on his degree of information. According to the degree of information they provide, the sources of information are divided into primary, secondary and tertiary; This division is generally used in the academic field.
\end{abstract}

Keywords:

Information, search, researcher

\section{Resumen:}

Las fuentes de información son instrumentos para el conocimiento, acceso y búsqueda de la información, su objetivo principal es el de buscar, fijar y difundir la fuente de información implícita en cualquier soporte físico, estas se pueden catalogar desde diferentes perspectivas, sin embargo, cada autor puede elaborar su propia clasificación dependiendo su grado de información. De acuerdo con el grado de información que proporcionan, las fuentes de información se dividen en primarias, secundarias y terciarias; esta división se utiliza generalmente en el ámbito académico.

\section{Palabras Clave:}

Información, búsqueda, investigador

\section{Introducción}

Las fuentes de información constituyen un concepto muy amplio. A lo largo de la historia el concepto de estas ha ido evolucionando desde propuestas que lo emparejaban con las bibliografías y las obras de referencia [1].

Desde siempre el hombre ha sentido la necesidad de registrar de una forma u otra la producción bibliográfica para:

- Tener elementos que permitan la selección y adquisición de documentos.

- Facilitar el acceso a documentos coleccionados en bibliotecas.

- Facilitar la identificación erudita.

Con la aparición de las Tecnologías de Información y Comunicación (TIC) en el mundo de la documentación ha provocado la aparición de nuevas tipologías de fuentes o la transformación de otras ya existentes. Por esta razón, a veces, la distinción entre tipologías puede resultar bastante confusa.
Pero, hoy en día, las fuentes de información abarcan muchos más recursos que la bibliografía.

Existe también la tendencia a identificar las fuentes de información con las obras de referencia. Éstas son fuentes de información de carácter documental utilizadas habitualmente en el servicio de referencia de bibliotecas y de centros de documentación para atender a las demandas informativas de los usuarios [2].

La confusión terminológica que se ha creado sobre el concepto de "fuentes de información" lleva consigo una gran dificultad para clasificar las distintas fuentes de información.

Son muchos los autores que se han atrevido a sistematizar las obras y las fuentes de información, utilizando para ello una gran diversidad de criterios específicos: temática, cobertura, soporte, sistemas de acceso, etc.; no obstante, son muchos los factores que 
imposibilitan llegar a un acuerdo de clasificación definitiva y unificada por parte de los expertos en este tema.

Entre estos factores se destaca la heterogeneidad de los recursos de información disponibles, las formas y medios surgidos con la difusión de las redes, las nuevas tecnologías y el carácter híbrido de muchas de estas fuentes de información.

Dado que no se puede adoptar un único criterio de clasificación, nuestro modelo para clasificar y describir las fuentes de información partirá del modelo más clásico y frecuentemente utilizado por los diferentes autores: el grado de información.

Este criterio es uno de los más utilizados entre los usuarios y las unidades de la información, ya que clasifica las fuentes según el grado de elaboración o nivel de información que proporcionan en fuentes de información primarias, secundarias y terciarias [3].

\section{Referencias}

[1] Gallego, J. (s.f). Fuentes y servicios de información, Recuperado y consultado el 8 de julio de 2019 de: http://openaccess.uoc.edu/webapps/o2/bitstream/10609/241/5/F uentes\%20de\%20informaci\%C3\%B3n\%20I_M\%C3\%B3dulo\%2 01 Fuentes\%20y\%20servicios\%20de\%20informaci\%C3\%B3n.p df

[2] Miranda, U. (2008). Fuentes de Información para la recolección de información cuantitativa y cualitativa. Recuperado y consultado el 8 de julio de 2019 de: http://docs.bvsalud.org/biblioref/2018/06/885032/texto-no-2fuentes-de-informacion.pdf

[3] Huamán, D. (2011). Fuentes de Información. Curso. Módulo1. Fuentes de Información. Centro de gestión de conocimiento. Recuperado y consultado el 8 de julio de 2019 de: http://bvsper.paho.org/videosdigitales/matedu/cam2011/Fuentes informacion.pdf?ua $=1$

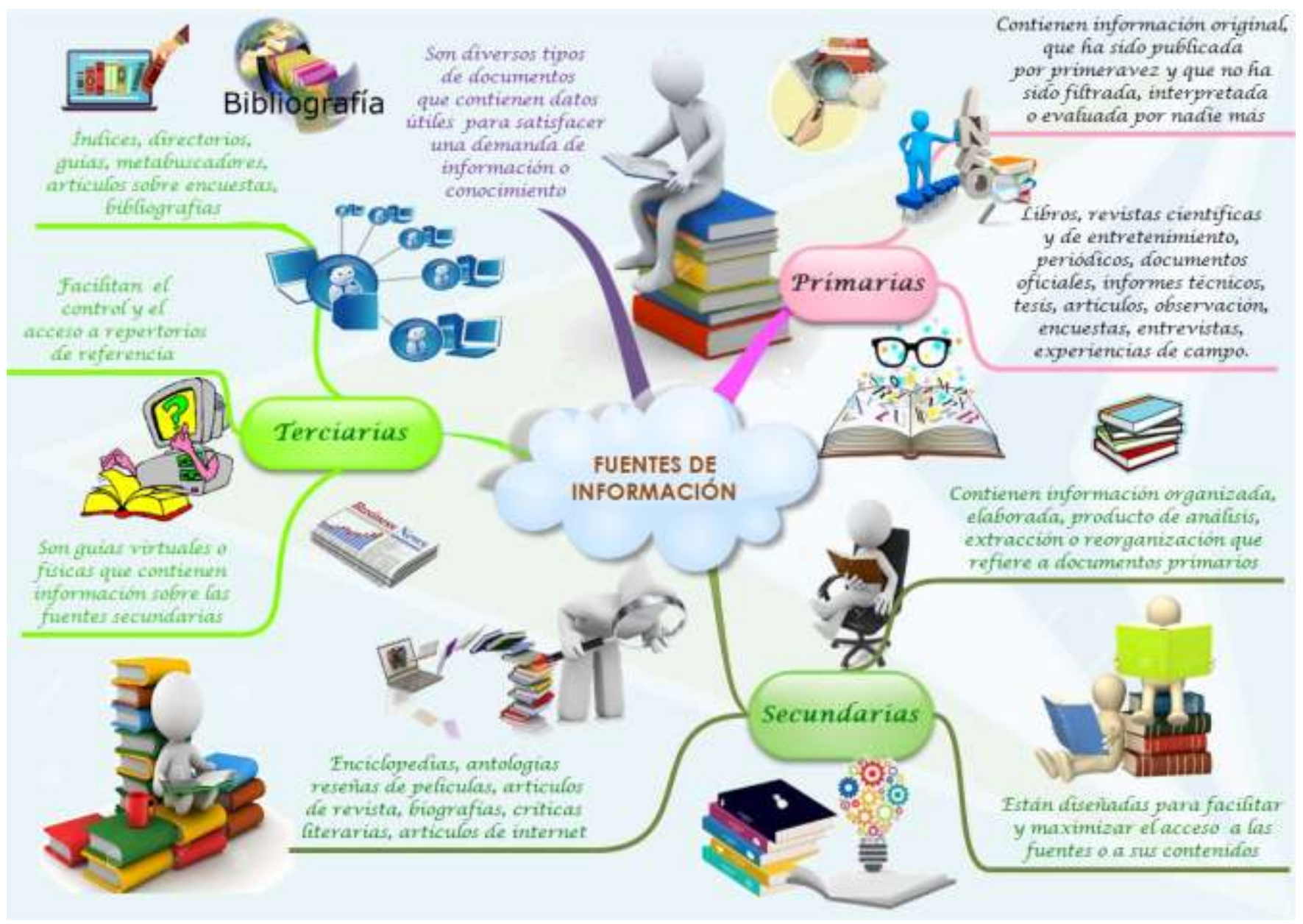

Figura 1; De Construcción Propia; Esquema de las Fuentes de Información 